\title{
Revisiting the Rate-Limiting Step of the ANS-Protein Binding at the Protein Surface and Inside the Hydrophobic Cavity
}

\author{
Chikashi Ota ${ }^{1}$, Shun-ichi Tanaka ${ }^{2}$ and Kazufumi Takano ${ }^{2, *}$ D \\ 1 College of Life Sciences, Ritsumeikan University, Kusatsu, Shiga 525-8577, Japan \\ 2 Department of Biomolecular Chemistry, Kyoto Prefectural University, Sakyo-ku, Kyoto 606-8522, Japan; \\ stanaka1@kpu.ac.jp \\ * Correspondence: takano@kpu.ac.jp; Tel./Fax: +81-75-703-5654
}

check for updates

Citation: Ota, C.; Tanaka, S.-i.; Takano, K. Revisiting the Rate-Limiting Step of the ANS-Protein Binding at the Protein Surface and Inside the Hydrophobic Cavity. Molecules 2021, 26, 420. https: / /doi.org/10.3390/ molecules 26020420

Academic Editor: Makoto Tsunoda Received: 18 December 2020 Accepted: 12 January 2021 Published: 14 January 2021

Publisher's Note: MDPI stays neutral with regard to jurisdictional clai$\mathrm{ms}$ in published maps and institutional affiliations.

Copyright: (C) 2021 by the authors. Licensee MDPI, Basel, Switzerland. This article is an open access article distributed under the terms and conditions of the Creative Commons Attribution (CC BY) license (https:// creativecommons.org/licenses/by/ $4.0 /)$.

\begin{abstract}
Anilino-1-naphthalenesulfonic acid (ANS) is used as a hydrophobic fluorescence probe due to its high intensity in hydrophobic environments, and also as a microenvironment probe because of its unique ability to exhibit peak shift and intensity change depending on the surrounding solvent environment. The difference in fluorescence can not only be caused by the microenvironment but can also be affected by the binding affinity, which is represented by the binding constant $(K)$. However, the overall binding process considering the binding constant is not fully understood, which requires the ANS fluorescence binding mechanism to be examined. In this study, to reveal the rate-limiting step of the ANS-protein binding process, protein concentration-dependent measurements of the ANS fluorescence of lysozyme and bovine serum albumin were performed, and the binding constants were analyzed. The results suggest that the main factor of the binding process is the microenvironment at the binding site, which restricts the attached ANS molecule, rather than the attractive diffusionlimited association. The molecular mechanism of ANS-protein binding will help us to interpret the molecular motions of ANS molecules at the binding site in detail, especially with respect to an equilibrium perspective.
\end{abstract}

Keywords: fluorescence; 8-anilino-1-naphthalenesulfonic acid; protein binding; hydrophobic probe

\section{Introduction}

The chemical compound 8-Anilino-1-naphthalenesulfonic acid (ANS) (Figure 1a) has been used as a hydrophobic fluorescence probe for more than five decades, mainly in biochemical and biological research [1-4], because of its high fluorescence intensity in hydrophobic environments. ANS has been used to detect protein aggregation and protein denaturation $[5,6]$. The absorption and fluorescence spectra of ANS in water, as well as the fluorescence in solutions of lysozyme $(1.0 \mathrm{mg} / \mathrm{mL})$ and bovine serum albumin (BSA) $(1.0 \mathrm{mg} / \mathrm{mL})$, are shown in Figure $1 \mathrm{~b}, \mathrm{c}$, indicating that both the band position and intensity of ANS fluorescence show significant differences depending on the microenvironments around the binding site of proteins $[4,7,8]$. Furthermore, a large difference in fluorescence can be caused by the microenvironment and binding affinity (represented by the binding constant, $K)$. The binding constants between ANS and proteins from previous studies are plotted in Figure 2a, indicating that the $K$ values show a large dispersion by two or three orders of magnitude among proteins [9-13].

A previous thermodynamic study using calorimetric enthalpy measurement [14] however, showed that the binding enthalpies of various proteins, including lysozyme and BSA, do not differ significantly with the main conclusion that ion-pair formation between the negatively charged sulfonate group of ANS and the positively charged amino acid residues of proteins (such as Lys and Arg) is the primary driving force for ANS-protein binding; this has also been elucidated by other protein structural analyses [15-18]. To clarify the cause of the large dispersion of the binding constants, knowledge of the interaction at the binding site and an understanding of the overall binding process, including the 
initial process before binding, are essential, requiring a detailed understanding of each component step and its impact.

(a)<smiles>O=S(=O)(O)c1cccc2cccc(Nc3ccccc3)c12</smiles>

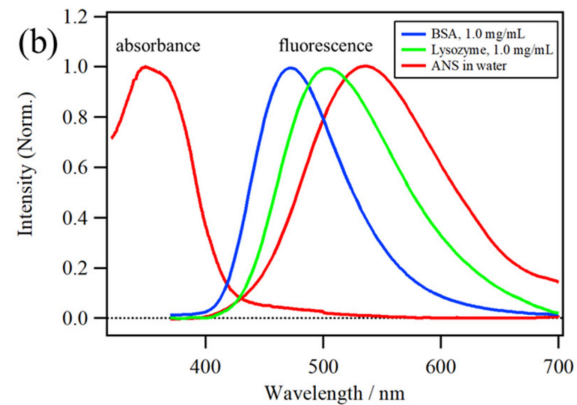

(c)

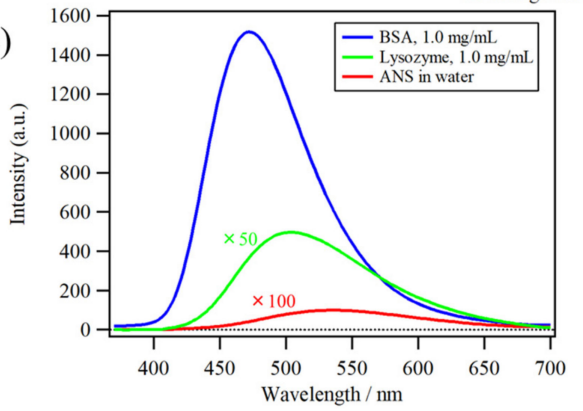

Figure 1. (a) Molecular structure of 8-anilino-1-naphthalenesulfonic acid (ANS). (b) Normalized absorption and fluorescence spectra of ANS in water, as well as normalized fluorescence spectra solutions of lysozyme $(1.0 \mathrm{mg} / \mathrm{mL})$ and bovine serum albumin (BSA) $(1.0 \mathrm{mg} / \mathrm{mL})$. (c) Comparison of the fluorescence spectrum of BSA $(1.0 \mathrm{mg} / \mathrm{mL})$ solution with that of water and lysozyme solution.

(a)

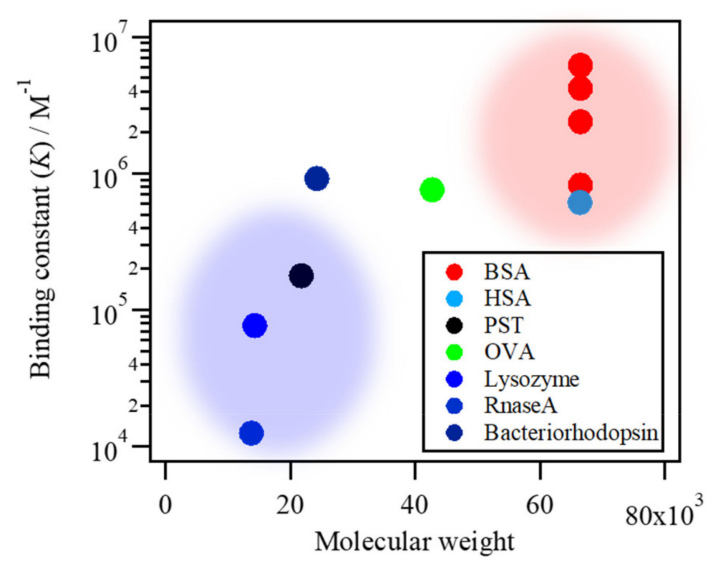

(b)

(i)

(ii)
Protein + ANS $\rightleftarrows$ Protein $\cdots \cdot$ ANS $\rightleftarrows$ Protein - ANS
Unbound Transient Complex
Bound

Figure 2. (a) The ANS-protein binding constants (K) of various proteins [9-13]. (b) An assumption about the ANS-protein binding processes.

In the current study, to elucidate the rate-limiting step of the ANS-protein binding process, protein concentration-dependent ANS fluorescence measurements were performed using lysozyme and BSA solutions under various $\mathrm{pH}$ conditions. To analyze the binding constant of each condition, we assumed that the overall binding process consists of (i) diffusion-limited association as an initial binding step and (ii) the stabilization process by interaction at the binding site as a latter one through a transient complex state as a represen- 
tative state appearing in the binding pathways that leads the unbound state to the bound complex (Figure 2b) [19,20]. Based on the aforementioned model, the protein concentrationdependent measurements of ANS fluorescence were analyzed in detail. The effects of the initial and latter binding processes were compared by preparing comparable conditions in the two binding processes. In the initial binding step, the effect of the diffusion-limited association for the overall binding constant was estimated by comparing the ANS-lysozyme binding constants under $\mathrm{pH}$ conditions of $\mathrm{pH} 8.0,5.5$, and 3.0 because the net charge of the lysozyme increases as the $\mathrm{pH}$ decreases [21,22], wherein a strong electrostatic attraction between the ANS and lysozyme is expected, which should promote the association. In the latter binding step, the effect of the binding interaction at the binding sites on the protein surface and inside the hydrophobic cavity was estimated by comparing the $K$ values of the lysozyme and BSA solutions. Based on the analysis of the experimental results, the free energy surface of the ANS-protein binding was described and the rate-limiting step of the overall process was suggested.

\section{Results}

\subsection{Molecular Docking Analysis}

Before starting the spectroscopic analysis of ANS fluorescence upon binding to proteins, a molecular docking analysis using SwissDock was performed to ascertain the ANS binding site of the proteins $[23,24]$. Under the protein concentration measurements, in which the amount of protein was excessive compared to that of the ANS molecules, the most preferable binding site had the lowest $\Delta \mathrm{G}$.

Figure $3 a, b$ show the ANS binding sites of the lysozyme and BSA, which have the lowest $\Delta G$ among the various binding sites. The binding site of lysozyme is located at $\operatorname{Arg}^{125}$ on the protein surface (Figure 3a), and the binding site of BSA is located inside the hydrophobic pocket with three hydrogen bonds with Lys ${ }^{114}$, Arg ${ }^{185}$, and Arg ${ }^{427}$ (Figure 3b). Previous studies have suggested that ANS molecules can bind to positively charged amino acid residues, such as Lys and Arg, at the protein surface through ion-pair interaction [14-18]. Lysozyme has several Lys and Arg residues on its protein surface [4,25]; thus, $\operatorname{Arg}^{125}$ can be the most preferable site for ANS molecules. In contrast, in BSA ANS molecules can be confined inside the hydrophobic pockets of the protein and the principal binding sites are located in the subdomains IIA and IIIA [12,26-28]. Here, the estimated binding site in Figure $3 b$ is inside subdomain IIIA; thus, the results acquired by the current simulation agree with the previous results. The estimated $\Delta G$ values for the ANS binding site of lysozyme and BSA were -7.1 and $-8.6 \mathrm{kcal} / \mathrm{mol}$, respectively, indicating that the ANS binding site of BSA is more stable than that of lysozyme.

(a)

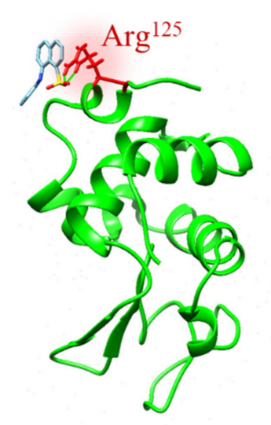

(b)

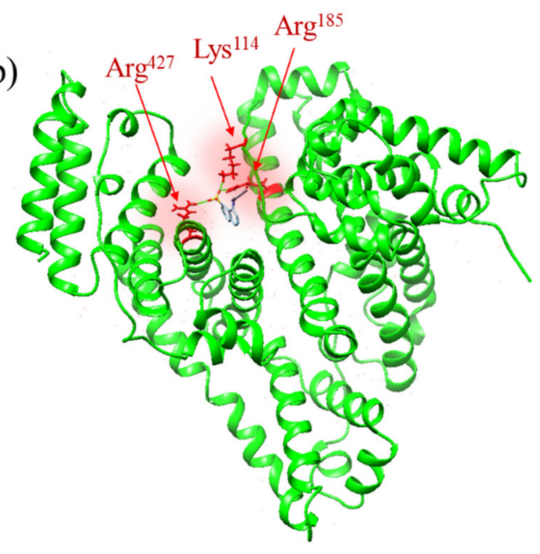

Figure 3. Estimated ANS binding sites of (a) lysozyme and (b) BSA, which has the lowest $\Delta \mathrm{G}$ among the various binding sites. (a) The binding site of lysozyme is located at $\mathrm{Arg}^{125}$ on the protein surface, and (b) the binding site of BSA is located inside the hydrophobic pocket with three hydrogen bonds with $\mathrm{Lys}^{114}$, $\mathrm{Arg}^{185}$, and $\mathrm{Arg}^{427}$. 


\subsection{Protein Concentration Dependence of ANS Fluorescence}

A protein concentration-dependent measurement of the ANS fluorescence was performed to estimate the binding constant of the ANS-protein binding. To evaluate the binding affinity of the most preferable site, the protein concentration was increased with a lower ANS concentration $(30 \mu \mathrm{M})$. Figure $4 \mathrm{a}, \mathrm{b}$ show the lysozyme $(\mathrm{pH} 8.0)$ and BSA ( $\mathrm{pH}$ 7.0) concentration dependences of the ANS fluorescence. The protein concentrations were $0.1,0.5,1.0,5.0,10,50$, and $100 \mathrm{mg} / \mathrm{mL}$. The ANS fluorescence of the lysozyme solutions gradually increased as the protein concentration increased, indicating the gradual ANS binding to the lysozyme molecule (Figure 4a). The ANS fluorescence of the BSA solutions immediately increased after $0.1 \mathrm{mg} / \mathrm{mL}$, implying a high affinity between ANS and BSA (Figure $4 \mathrm{~b}$ ). On the other hand, the fluorescence decreased after $1.0 \mathrm{mg} / \mathrm{mL}$ because of the decrease in the throughput of the excitation light at $350 \mathrm{~nm}$, which could be caused by increased absorbance in the near-UV region of BSA [4].
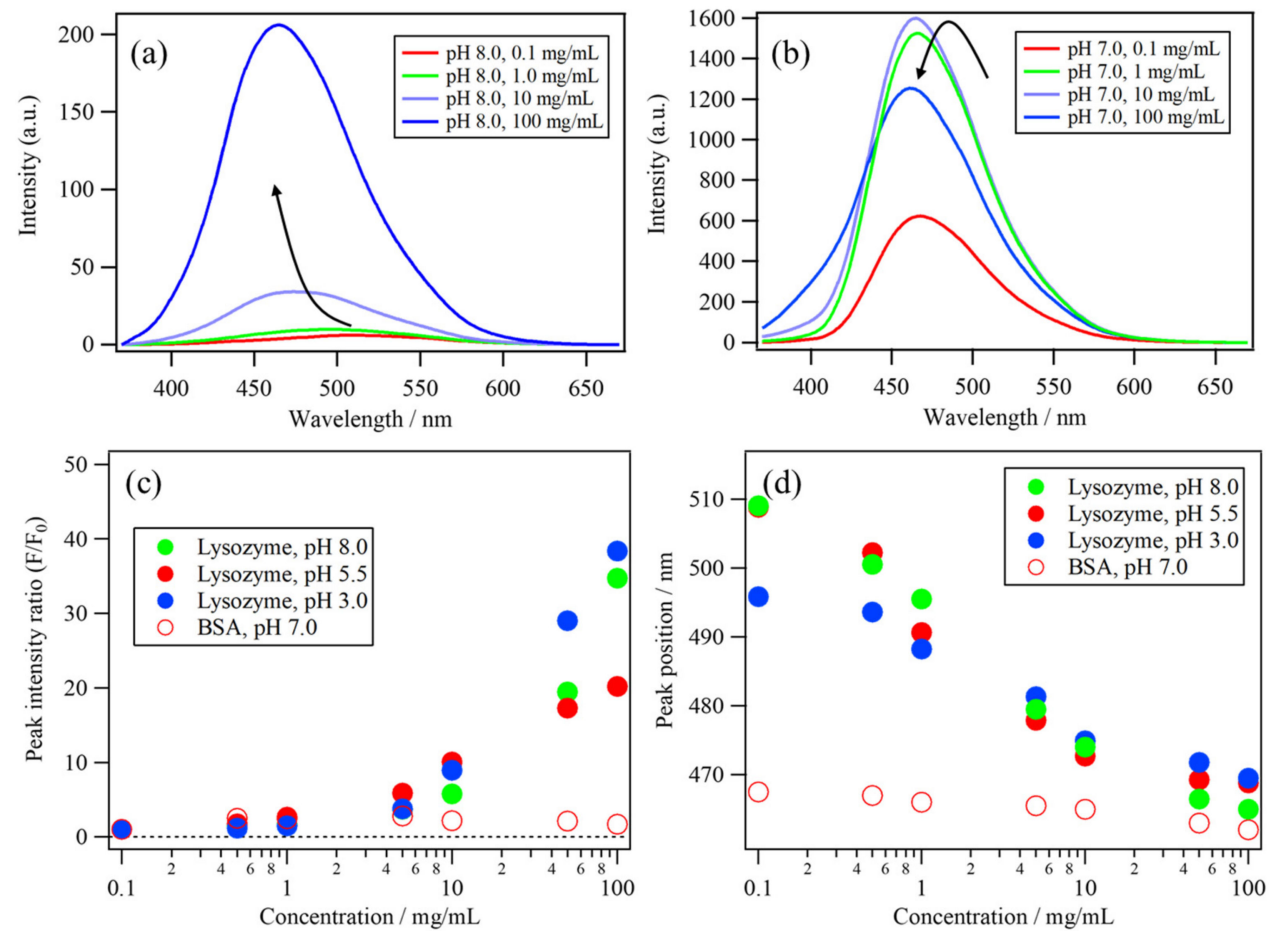

Figure 4. The protein concentration dependences of the ANS fluorescence of (a) lysozyme solution (pH 8.0) and (b) BSA solution ( $\mathrm{pH}$ 7.0). The protein concentration dependences of $(\mathrm{c})$ the peak intensity ratio $\left(\mathrm{F} / \mathrm{F}_{0}\right)$ and $(\mathrm{d})$ the peak position of the ANS fluorescence band of lysozyme at $\mathrm{pH} 8.0,5.5$, and 3.0 and of BSA at pH 7.0.

Figure $4 \mathrm{c}$ shows the protein concentration dependences of the peak intensity ratio $\left(\mathrm{F} / \mathrm{F}_{0}\right)$ and Figure $4 \mathrm{~d}$ shows the peak position of the ANS fluorescence band of lysozyme solutions at $\mathrm{pH} 8.0,5.5$, and 3.0, as well as BSA at $\mathrm{pH}$ 7.0. Both the peak intensity ratio and its position in the lysozyme solutions gradually changed as the concentration increased. In contrast, those of BSA did not show a significant change because the ANS fluorescence intensity and the position of the BSA solution immediately changed at lower concentrations. To understand these changes in the ANS fluorescence of the lysozyme and BSA solutions in detail, principal component analysis (PCA) and multivariate curve resolutionalternating least squares (MCR-ALS) were applied to these datasets, as described in the subsequent section [29-32].

\subsection{MCR-ALS Analysis of the Protein Concentration Dependence of ANS Fluorescence Spectra}

The number of components in the datasets of the lysozyme concentration dependence of ANS fluorescence at $\mathrm{pH} 8.0,5.5$, and 3.0 was analyzed by an eigenvalue plot using PCA, 
which then indicated that the datasets mainly had two components in these concentration ranges. Thus, based on the two-component approximation, MCR-ALS was applied to resolve the spectral datasets.

Figure $5 \mathrm{a}$ shows the MCR loadings and Figure $5 \mathrm{~b}$ shows the scores of the ANS fluorescence spectra of the lysozyme solutions at $\mathrm{pH}$ 8.0, 5.5, and 3.0. The first MCR loading (red line) has a red-shifted peak maximum at approximately $500 \mathrm{~nm}$ compared to the second MCR loading (blue line) with a peak maximum at approximately $470 \mathrm{~nm}$. The first MCR loading can be assigned to free ANS molecules that are diffusing in water or that are a part of the ANS molecules binding to lysozyme because ANS molecules in hydrophilic environments have a red-shifted weak fluorescence from the charge-transfer (CT) electronic state, which transitions from the non-planar (NP) excited state with the rotation of the phenylamino group $[2,4,18,33]$. The second MCR loading, with a blueshifted peak at approximately $470 \mathrm{~nm}$, can be assigned to the ANS molecules binding to the protein surface, because both the restriction of water reorientation for ANS molecules in the protein hydration layer $[4,34,35]$ and the steric restriction of the ANS conformation at the binding site [12,36] can prevent transition from the NP state to the CT state, resulting in a blue-shift in the ANS fluorescence. The scores belonging to MCR Score 1 of the lysozyme solutions at $\mathrm{pH}$ 8.0, 5.5, and 3.0 (red circle) in Figure $5 \mathrm{~b}$ show a decrease with an increase in the protein concentration, while those of MCR Score 2 (blue circle) show an increase with an increase in concentration.
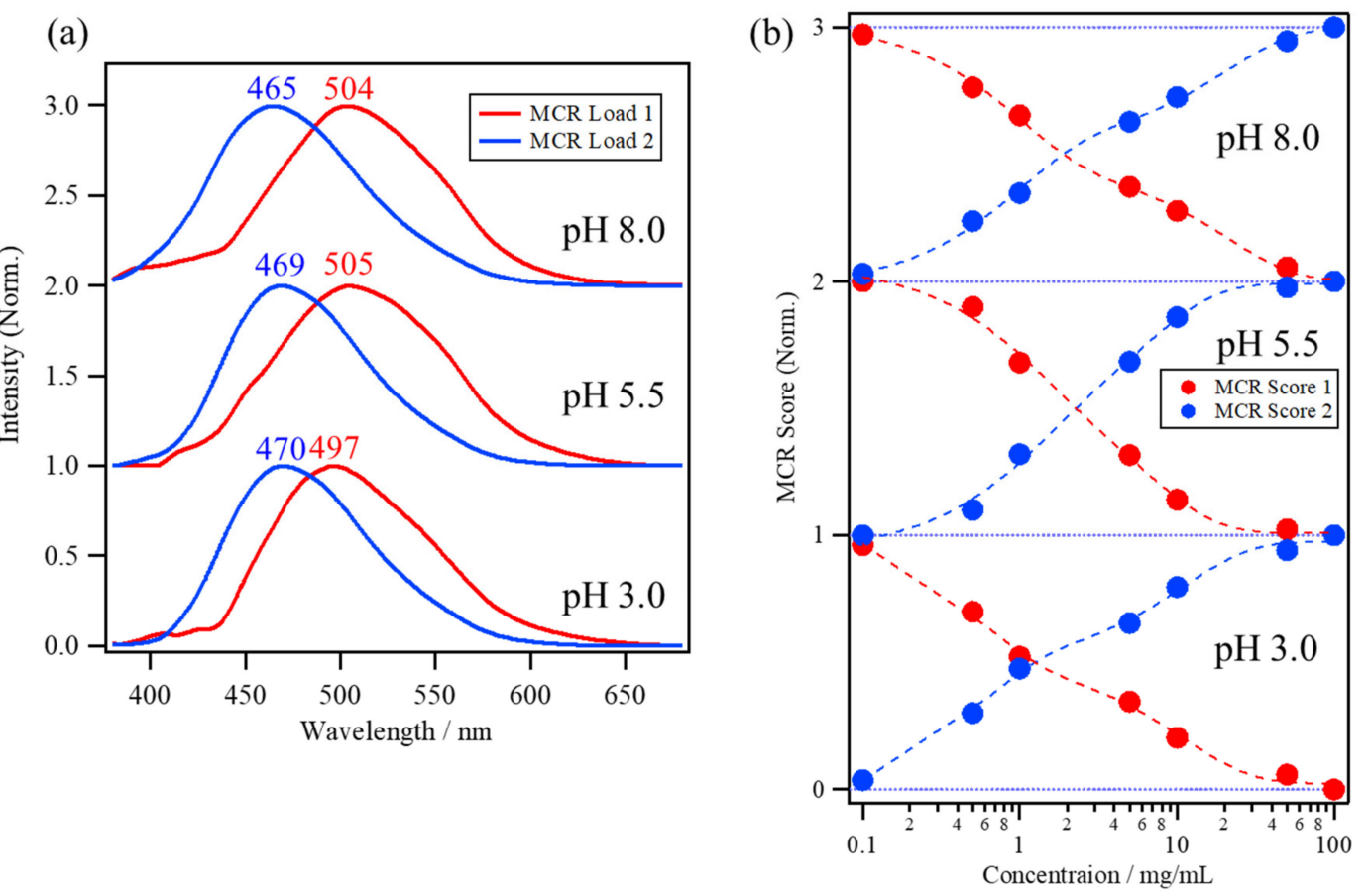

Figure 5. (a) The multivariate curve resolution (MCR) loadings and (b) scores of the ANS fluorescence spectra of lysozyme solutions at $\mathrm{pH} 8.0,5.5$, and 3.0.

The number of components in the datasets of the BSA concentration dependence of ANS fluorescence at $\mathrm{pH} 7.0$ was analyzed by the eigenvalue plot using PCA, which then indicated that the datasets had mainly three components in this concentration range. Thus, based on the three-component approximation, MCR-ALS was applied to resolve the spectral dataset. Figure $6 a$ shows the MCR loadings and Figure $6 \mathrm{~b}$ shows the scores of the ANS fluorescence spectra of the BSA solution at $\mathrm{pH} 7.0$ in the lower portion, with those of the lysozyme solution at $\mathrm{pH} 8.0$ as a reference in the upper portion. The first, second, and third MCR loadings have peak maxima at around 483, 465, and $415 \mathrm{~nm}$, respectively. The first MCR loading, with a peak at $483 \mathrm{~nm}$, is blue-shifted compared to that in the lysozyme solution at $504 \mathrm{~nm}$, implying that a large number of ANS molecules were already 
bound to BSA in the lower concentration range because of its high affinity with ANS molecules. The second loading is much more blue-shifted compared to the first, and is located at the same peak position as the lysozyme, which can be assigned to the ANS molecules binding to the hydrophobic pockets of BSA. The third loading, with a peak at $415 \mathrm{~nm}$, can be assigned to the intrinsic protein fluorescence at the oligomeric interface of BSA oligomers because of the delocalization of the electrons of protein backbones at the interface by the weak hydrogen bond and / or $\pi-\pi$ stacking interactions $[4,31,37,38]$.
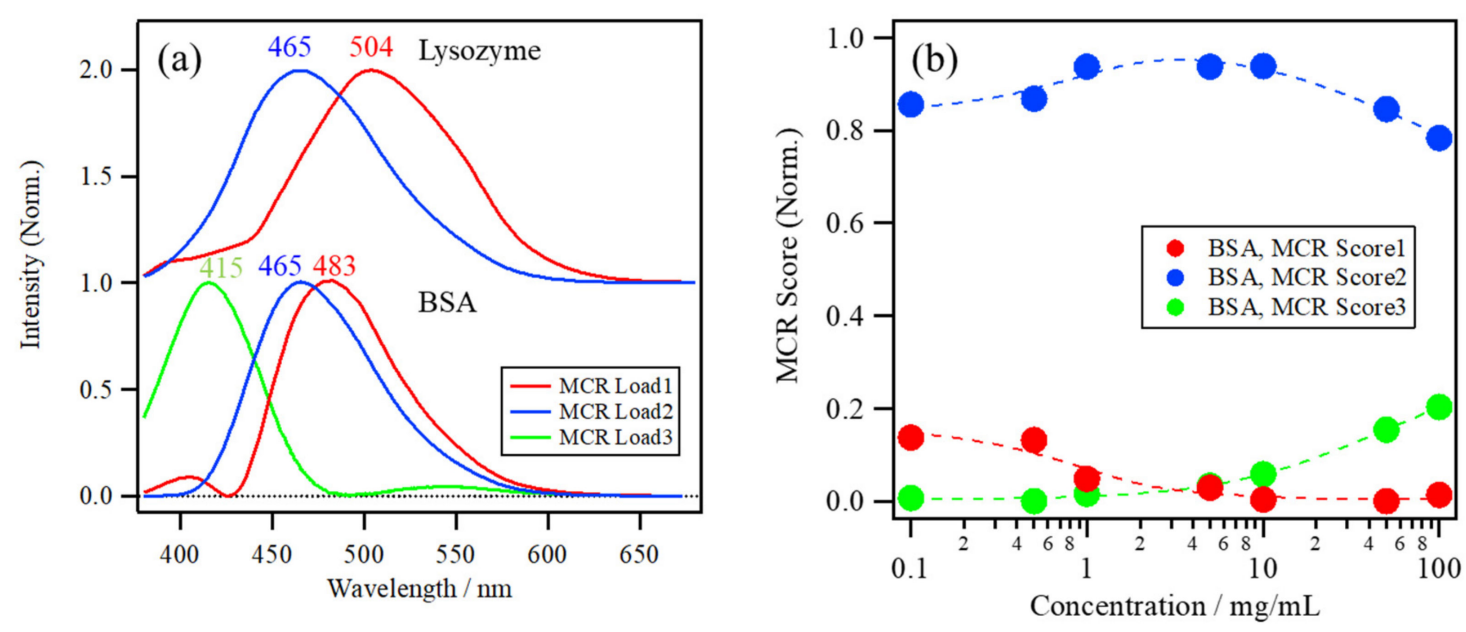

Figure 6. (a) The MCR loadings and (b) scores of the ANS fluorescence spectra of the BSA solution at pH 7.0, with those of the lysozyme solution at $\mathrm{pH} 8.0$ as a reference.

MCR Score 1 of the BSA solution in Figure $6 \mathrm{~b}$ was only a small part of the overall score and shows a gradual decrease with an increase in the protein concentration, while MCR Score 2 is dominant throughout the entire concentration range, especially at $>1.0 \mathrm{mg} / \mathrm{mL}$, indicating the high binding affinity of ANS to BSA. On the other hand, MCR Score 3 starts to increase in the higher concentration range after $10 \mathrm{mg} / \mathrm{mL}$, caused by the intrinsic fluorescence induced by BSA oligomerization. MCR Score 3 is not directly related to the ANS binding. Therefore, only MCR Scores 1 and 2 have been focused on for the analysis of the ANS-protein binding constant.

\subsection{Estimation of the ANS-Protein Binding Constant}

To compare the binding affinity of ANS to proteins of each protein solution, the binding constant was estimated based on the following assumption of the equilibrium relation $[39,40]$ :

$$
K=\frac{C_{R}(M C R 2)}{C_{R}(M C R 1)[\text { Protein }]}
$$

where $C_{R}(M C R 1)$ and $C_{R}(M C R 2)$ are the normalized MCR scores 1 and 2 and [Protein] is the protein concentration of the lysozyme and BSA solutions. Based on the assumption shown above, the binding constant can be estimated using Equation (2) [39,40]:

$$
C_{R}(M C R 2)=\frac{K[\text { Protein }]}{1+K[\text { Protein }]} .
$$

It should be noted that the protein concentration is excessive compared to the ANS concentration $(30 \mu \mathrm{M})$ in the protein concentration-dependent measurements; thus, the estimated binding constant can be assigned to the most preferable binding site of the overall protein surface.

The fitting results and the estimated $K$ values of these conditions are shown in Figure 7. The increase in the MCR Score 2 of the lysozyme solutions shifts to a lower concentration as the $\mathrm{pH}$ of the solutions decreases from 8.0 to 3.0 (Figure 7a). The estimated $K$ values of the 
lysozyme solutions at $\mathrm{pH} 8.0,5.5$, and 3.0 correspond to $5.8,6.2$, and $9.3 \mathrm{mM}^{-1}$, respectively, indicating that the estimated $K$ values of the lysozyme solutions at $\mathrm{pH} 8.0,5.5$, and 3.0 slightly increase as the $\mathrm{pH}$ decreases and that the $K$ value at $\mathrm{pH} 3.0$ is approximately 1.6 times larger than that at $\mathrm{pH} 8.0$ (Figure $7 \mathrm{~b}$ ). The net charge of the lysozyme was estimated as a function of $\mathrm{pH}$ from the number of individual acidic and basic amino acid residues and their corresponding acidity constants using the web server $\mathrm{H}++$ at http:/ / biophysics.cs.vt.edu/index.php [21,22,41]. The net charge of the lysozyme increases as $\mathrm{pH}$ decreases because of the protonation of amino acid residues. It should be noted that the immediate increase in the net charge from $\mathrm{pH} 5.5$ to $\mathrm{pH} 3.0$ is related to the increase in the $K$ value of the lysozyme solutions, suggesting that the increase in the net charge of the lysozyme can promote ANS binding to the lysozyme.

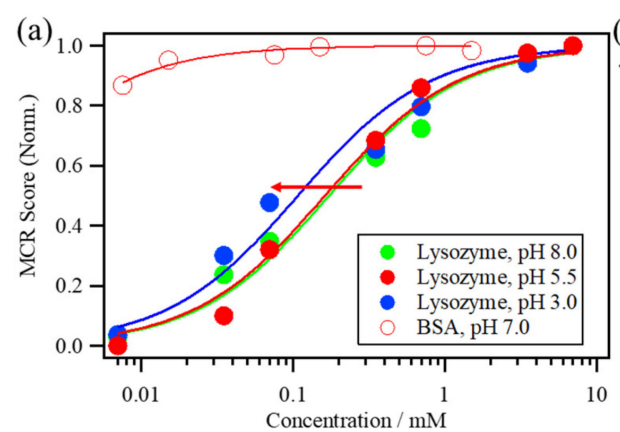

(c)

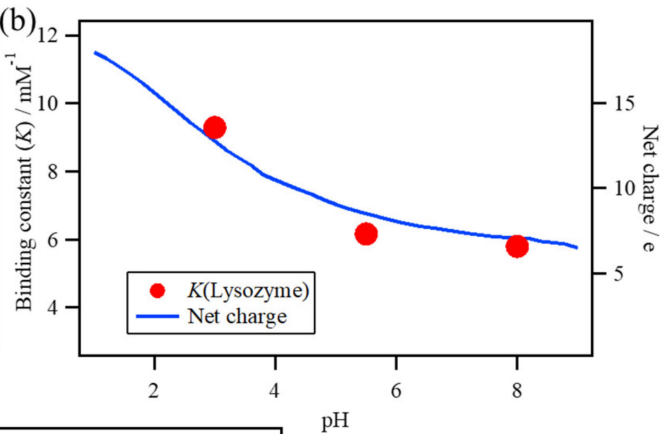

$\mathrm{pH}$

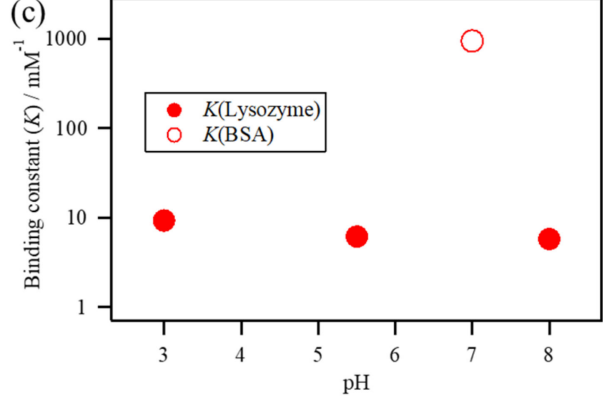

Figure 7. (a) The increase in MCR Score 2 of the lysozyme solutions at $\mathrm{pH} 8.0,5.5$, and 3.0 and the BSA solution plotted against the protein concentration. (b) The estimated $K$ value of the lysozyme solutions at $\mathrm{pH} 8.0,5.5$, and 3.0 with the calculated net charge of lysozyme as a function of $\mathrm{pH}$. (c) The estimated $K$ value of the ANS-BSA binding with one of the lysozyme solutions.

The increase in MCR Score 2 of BSA has a high score value even at lower concentrations because of its high affinity (Figure $7 a$ ). The estimated $K$ value of BSA corresponds to $940 \mathrm{mM}^{-1}$, which is higher than that of lysozyme by two orders of magnitude and is 160 times larger than that of lysozyme at $\mathrm{pH}$ 8.0, as shown in Figure 7c.

\section{Discussion}

\subsection{Effect of the Electrostatic Association on the ANS-Protein Binding Pathway}

To estimate the effect of the diffusion-limited association as well as the binding interaction at the binding site, the protein concentration dependence of ANS was measured using lysozyme and BSA solutions as a case study. Lysozyme concentration-dependent measurements of ANS fluorescence at various $\mathrm{pH}$ values were performed to estimate the binding constant, indicating that the $K$ value of lysozyme increased by 1.6 times from $\mathrm{pH} 8.0$ to $\mathrm{pH}$ 3.0. The $\mathrm{pH}$-dependent increase in the $K$ value can be caused by the electrostatically assisted association between the negatively charged sulfonate group of ANS and the increasing positively charged lysozyme with the decrease in $\mathrm{pH}$ of the solutions.

Previous studies have shown an electrostatic association by accelerated diffusion in the binding interfaces of protein complexes [19,42,43]. Schreiber and Fersht showed a rapid, electrostatically assisted association between barnase and its intracellular inhibitor 
barstar using the electrostatic screening effect of $\mathrm{NaCl}$ [42]. The binding site of barnase is positively charged, whereas that of barstar has complementary negative charges, causing electrostatically assisted association at the oppositely charged interface. They showed a linear correlation between the association rate constant $\left(\mathrm{k}_{1}\right)$ and the electrostatic contribution to the mean rational activity coefficient of $\mathrm{NaCl}\left(f_{ \pm}^{*}\right)$, which was calculated using the Debye-Hückel equation. This suggests that the rate-limiting step for an association is dictated mainly by the electrostatic potential between the two proteins, because $\log f_{ \pm}^{*}$ is directly related to the electrostatic potential and $\log \mathrm{k}_{1}$ is directly related to the activation energy. The association rate constant was changed from $5 \times 10^{9}$ to $10^{5}$, a change of order corresponding to $\mathrm{NaCl}$ concentrations ranging from $5 \mathrm{mM}$ to $2000 \mathrm{mM}$.

The association rate constant between barnase and barstar with $\mathrm{NaCl}$ concentrations from $2000 \mathrm{mM}$ to $5 \mathrm{mM}$ increased by four orders of magnitude, while the binding constant between ANS and lysozyme increased by 1.6 times from $\mathrm{pH} 8.0$ to $\mathrm{pH} 3.0$, suggesting that a rapid electrostatically assisted association cannot be achieved in ANS-lysozyme binding because the fraction of the reaction area (binding interface) was only a small portion of the overall protein and is much smaller compared to that associated with the case of the association between barnase and barstar. Therefore, in ANS-lysozyme binding, the acceleration effect due to the electrostatic association can only contribute a small part to the diffusion-limited association.

\subsection{Effects of the Binding Interaction on the ANS-Protein Binding Pathway}

Comparison of the estimated $K$ value for the ANS-BSA binding with that of lysozyme (Figure 7c) showed that the estimated $K$ value of BSA was much higher than that of lysozyme by two orders of magnitude. One of the critical factors behind the high affinity of BSA could be expected by the binding enthalpy at the binding site because the binding enthalpy primarily reflects the strength of the interaction between ANS and the bound protein. Matulis and Lovrien estimated the enthalpies of binding ANS to four proteins (BSA, lysozyme, papain, and protease omega). They showed that the ANS binding enthalpies of one site in proteins have -4 to $-5 \mathrm{kcal} / \mathrm{mol}(-17$ to $-21 \mathrm{~kJ} / \mathrm{mol})$, whether the binding site is on the protein surface or inside the hydrophobic pocket, suggesting that the primary factor in the binding of ANS to proteins is electrostatic (Coulombic) interaction through ion-pair formation at the binding site [14]. In other words, the binding enthalpies hardly depend on the hydrophobic or hydrophilic environment surrounding the binding site. Therefore, the difference in $K$ value between BSA and lysozyme cannot be explained from the perspective of binding enthalpy at the binding site.

Previous studies of the dissociation constant of ANS-protein binding using the ANS concentration dependence measurement show that the dissociation constant of BSA has a smaller value of a few micromolars, such as 1.3 [44] or $5.0 \mu \mathrm{M}$ [26], compared to those of external sites, such as MurA (40.8 $\mu \mathrm{M})$ [16], Poly-Arg (2.9 mM), and Poly-Lys (2.6 mM) [18], suggesting that the low dissociation constant can be caused by the hydrophobic pocket of BSA. This supports the results of the present study, showing that the binding constant, the $K$ value of ANS-BSA binding, was much higher than that of ANS-lysozyme binding, in which the binding site is at the external site of proteins. Therefore, it can be suggested that the binding of ANS inside the hydrophobic pocket can restrict the dissociation of ANS from the binding site because of its confined environment, thereby increasing the $K$ value.

\subsection{Rate-Limiting Step of the Overall ANS-Protein Binding Pathway}

Based on the protein concentration dependence on ANS fluorescence using lysozyme and BSA solutions, the proposed free energy surface of the ANS-protein binding with the kinetic scheme of the association between ANS and protein molecules via the formation of the transient complex is shown in Figure 8. The ANS-protein binding can be classified as the interaction between a macromolecule and a small binding molecule; thus, the fraction corresponding to the active site is only a small part of the overall protein. Therefore, the diffusion-limited association process between the unbound state and transient complex 
state (red-colored part) has a small contribution to the overall binding process, as is experimentally shown in the small effect of the electrostatic acceleration by the increased net charge of the protein in the effect of $\mathrm{pH}$ on the ANS-lysozyme binding constant.
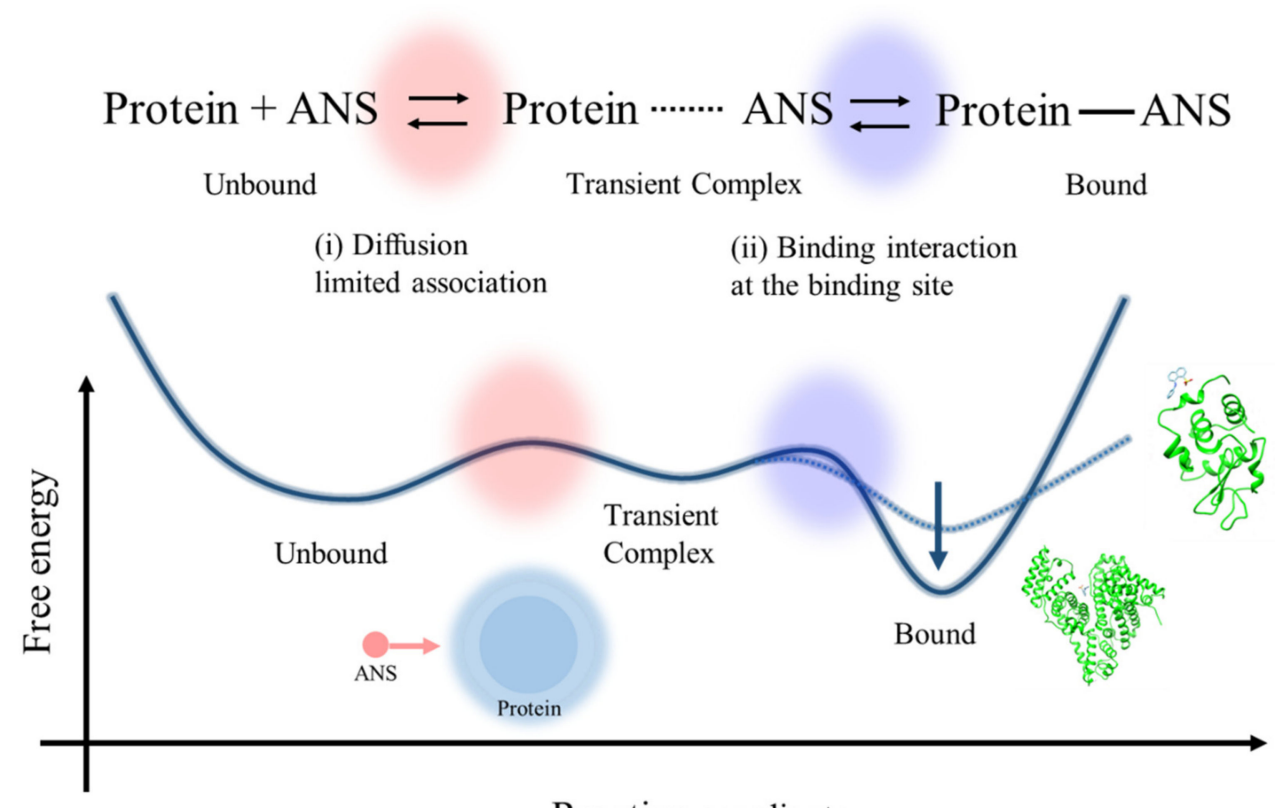

Reaction coordinate

Figure 8. The proposed free energy surface of the ANS-protein binding with the kinetic scheme of the association between ANS and protein molecules via the formation of the transient complex.

On the other hand, the latter process, after the initial binding (blue-colored part), can be rather crucial because the microenvironment around the binding site has a significant effect on the overall binding constant by stabilizing the binding state and preventing the dissociation process, as is evident experimentally in the comparison of the $K$ values of ANS-BSA binding in the case of lysozyme. The confined environment in the hydrophobic pockets of BSA can decrease the free energy of the bound state compared to the case of lysozyme, as shown in the molecular docking simulation (Figure 3). It can increase the potential barrier from the bound state to the transient complex state, as indicated by the small value of the dissociation constant of BSA in previous studies $[26,44]$.

Therefore, it can be suggested that the binding interaction at the binding site is the main factor affecting the binding constant of the overall ANS-protein binding process. The latter process from the transient complex state to the bound state is the main limiting step.

\section{Experimental Section}

\subsection{Fluorescence Measurement}

A protein concentration-dependent measurement of ANS fluorescence was performed to estimate the binding constant of ANS-protein binding. To evaluate the binding affinity of the most preferable site, the protein concentration was increased with a lower ANS concentration $(30 \mu \mathrm{M})$. The protein concentrations of the lysozyme and BSA solutions were prepared at $0.1,0.5,1.0,5.0,10,50$, and $100 \mathrm{mg} / \mathrm{mL}$. To investigate the effect of the diffusion-limited association on the overall binding constant, lysozyme solutions were prepared at $\mathrm{pH} 8.0,5.5$, and 3.0; citrate buffer solution $(20 \mathrm{mM})$ was used to establish pH 5.5 and 3.0, and Tris- $\mathrm{HCl}$ buffer solution $(20 \mathrm{mM})$ was used to establish $\mathrm{pH}$ 8.0. To compare the binding constants between lysozyme and BSA, the BSA solution was prepared at $\mathrm{pH} 7.0$ with $20 \mathrm{mM}$ of citrate buffer solution to evaluate the effect of the interaction at the binding site. 
The experimental setup for the measurement of fluorescence spectra has been previously described [4,7]. ANS fluorescence spectra were measured in a quartz cuvette using an F-2500 system (Hitachi, Ltd., Tokyo, Japan) with a right-angle geometry. The excitation wavelength was set to $350 \mathrm{~nm}$ and the spectral range was from 300 to $800 \mathrm{~nm}$ in $0.5 \mathrm{~nm}$ increments.

\subsection{Molecular Docking Analysis}

To estimate the ANS binding sites of lysozyme and BSA, a molecular docking analysis was carried out, using SwissDock at http:/ / www.swissdock.ch, which is a protein-small molecule docking web server $[23,24]$. SwissDock achieves a high success rate of the biding site prediction compared to other well-known protein docking tools [45]. SwissDock estimates the preferable binding sites of proteins based on the CHARMM22 force field calculating the van der Waals and electrostatic interaction energy between the ligand and the target protein. In addition, the solvent effect is taken into account using the FACTS (Fast Analytical Continuum Treatment of Solvation) implicit solvation model, which implicitly considers the solvent effect under the assumption of the continuum electrostatics models.

\section{Conclusions}

To clarify the rate-limiting step of the ANS-protein binding process, protein concentrationdependent measurements of ANS fluorescence were performed using lysozyme and BSA solutions. The diffusion-limited association process in the initial binding, which can be accelerated by the electrostatic association in the lower $\mathrm{pH}$ condition, has a small effect on the overall binding constant because the fraction corresponding to the binding site is only a small part of the overall protein. In contrast, after the initial binding the latter process has a larger effect on the binding constant, especially in the case of the binding site being in hydrophobic pockets, which prevents the dissociation of ANS from the site due to the confined environment. The results of this study suggest that the main factor affecting the ANS-protein binding process is the microenvironment at the binding site, via the restriction of the attached ANS molecule rather than the attractive diffusion-limited association between ANS and the protein. The molecular mechanism of ANS-protein binding will help us to interpret the molecular motions of ANS molecules at the binding site in detail, especially from the perspective of equilibrium.

Author Contributions: C.O. and K.T. conceived the experiments and wrote the paper. C.O. performed the experiments and analyzed the data. S.-i.T. technically supported the experiments and helped in the interpretation of data and the discussion of results. K.T. supervised. All authors have read and agreed to the published version of the manuscript.

Funding: This research received no external funding.

Acknowledgments: We thank our colleague Hikari Suzuki (Kyoto Prefectural University) for her kind assistance with our experiments.

Conflicts of Interest: The authors declare no conflict of interest.

\section{References}

1. Kosower, E.M.; Tanizawa, K. Analysis of Fluorescence Emission and Quenching for Molecules Bearing Latent Donors. Chem. Phys. Lett. 1972, 16, 419-425. [CrossRef]

2. Kosower, E.M. Intramolecular Donor-Acceptor Systems. 9. Photophysics of (Phenylamino)naphthalenesulfonates: A Paradigm for Excited-State Intramolecular Charge Transfer. Acc. Chem. Res. 1982, 15, 259-266. [CrossRef]

3. Kosower, E.M.; Huppert, D. Excited State Electron and Proton Transfers. Annu. Rev. Phys. Chem. 1986, 37, 127-156. [CrossRef]

4. Ota, C.; Takano, K. Spectroscopic Analysis of Protein-Crowded Environments Using the Charge-Transfer Fluorescence Probe 8-Anilino-1-Naphthalenesulfonic Acid. ChemPhysChem 2019, 20, 1456-1466. [CrossRef] [PubMed]

5. Hawe, A.; Sutter, M.; Jiskoot, W. Extrinsic Fluorescent Dyes as Tools for Protein Characterization. Pharm. Res. 2008, 25, 1487-1499. [CrossRef]

6. Kayser, V.; Chennamsetty, N.; Voynov, V.; Helk, B.; Trout, B.L. Conformational Stability and Aggregation of Therapeutic Monoclonal Antibodies Studied with ANS and Thioflavin T Binding. $m A b s$ 2011, 3, 408-411. [CrossRef] 
7. Ota, C.; Fukuda, Y.; Tanaka, S.; Takano, K. Spectroscopic Evidence of the Salt-Induced Conformational Change around the Localized Electric Charges on the Protein Surface of Fibronectin Type III. Langmuir 2020, 36, 14243-14254. [CrossRef]

8. Mukherjee, S.K.; Gautam, S.; Biswas, S.; Kundu, J.; Chowdhury, P.K. Do Macromolecular Crowding Agents Exert Only an Excluded Volume Effect? A Protein Solvation Study. J. Phys. Chem. B 2015, 119, 14145-14156. [CrossRef]

9. Cardamone, M.; Puri, N.K. Spectrofluorimetric Assessment of the Surface Hydrophobicity of Proteins. Biochem. J. 1992, 282, 589-593. [CrossRef]

10. Kuznetsova, I.M.; Sulatskaya, A.I.; Povarova, O.I.; Turoverov, K.K. Reevaluation of ANS Binding to Human and Bovine Serum Albumins: Key Role of Equilibrium Microdialysis in Ligand-Receptor Binding Characterization. PLoS ONE 2012, 7, e40845. [CrossRef]

11. Haskard, C.A.; Li-Chan, E.C.Y. Hydrophobicity of Bovine Serum Albumin and Ovalbumin Determined Using Uncharged (PRODAN) and Anionic (ANS ${ }^{-}$) Fluorescent Probes. J. Agric. Food Chem. 1998, 46, 2671-2677. [CrossRef]

12. Cattoni, D.I.; Kaufman, S.B.; Flecha, F.L.G. Kinetics and Thermodynamics of the Interaction of 1-Anilino-Naphthalene-8-Sulfonate with Proteins. Biochim. Biophys. Acta Proteins Proteom. 2009, 1794, 1700-1708. [CrossRef] [PubMed]

13. Cinar, H.; Winter, R. The Effects of Cosolutes and Crowding on the Kinetics of Protein Condensate Formation Based on Liquid-Liquid Phase Separation: A Pressure-Jump Relaxation Study. Sci. Rep. 2020, 10, 7245. [CrossRef] [PubMed]

14. Matulis, D.; Lovrien, R. 1-Anilino-8-Naphthalene Sulfonate Anion-Protein Binding Depends Primarily on Ion Pair Formation. Biophys. J. 1998, 74, 422-429. [CrossRef]

15. Ory, J.J.; Banaszak, L.J. Studies of the Ligand Binding Reaction of Adipocyte Lipid Binding Protein Using the Fluorescent Probe 1, 8-Anilinonaphthalene-8-Sulfonate. Biophys. J. 1999, 77, 1107-1116. [CrossRef]

16. Schonbrunn, E.; Eschenburg, S.; Luger, K.; Kabsch, W.; Amrhein, N. Structural Basis for the Interaction of the Fluorescence Probe 8-Anilino-1-Naphthalene Sulfonate (ANS) with the Antibiotic Target MurA. Proc. Natl. Acad. Sci. USA 2000, 97, 6345-6349. [CrossRef]

17. Lartigue, A.; Gruez, A.; Spinelli, S.; Rivière, S.; Brossut, R.; Tegoni, M.; Cambillau, C. The Crystal Structure of a Cockroach Pheromone-Binding Protein Suggests a New Ligand Binding and Release Mechanism. J. Biol. Chem. 2003, 278, 30213-30218. [CrossRef]

18. Gasymov, O.K.; Glasgow, B.J. ANS Fluorescence: Potential to Augment the Identification of the External Binding Sites of Proteins. Biochim. Biophys. Acta Proteins Proteom. 2007, 1774, 403-411. [CrossRef]

19. Zhou, H.X.; Pang, X. Electrostatic Interactions in Protein Structure, Folding, Binding, and Condensation. Chem. Rev. 2018, 118, 1691-1741. [CrossRef]

20. Kim, J.Y.; Meng, F.; Yoo, J.; Chung, H.S. Diffusion-limited association of disordered protein by non-native electrostatic interactions Nat. Commun. 2018, 9, 4707. [CrossRef]

21. Meissner, J.; Prause, A.; Bharti, B.; Findenegg, G.H. Characterization of Protein Adsorption onto Silica Nanoparticles: Influence of pH and Ionic Strength. Colloid Polym. Sci. 2015, 293, 3381-3391. [CrossRef] [PubMed]

22. Kubiak-Ossowska, K.; Cwieka, M.; Kaczynska, A.; Jachimska, B.; Mulheran, P.A. Lysozyme Adsorption at a Silica Surface Using Simulation and Experiment: Effects of pH on Protein Layer Structure. Phys. Chem. Chem. Phys. 2015, 17, 24070-24077. [CrossRef] [PubMed]

23. Grosdidier, A.; Zoete, V.; Michielin, O. Fast Docking Using the CHARMM Force Field with EADock DSS. J. Comput. Chem. 2011, 32, 2149-2159. [CrossRef] [PubMed]

24. Grosdidier, A.; Zoete, V.; Michielin, O. SwissDock, a Protein-Small Molecule Docking Web Service Based on EADock DSS. Nucleic Acids Res. 2011, 39, W270-W277. [CrossRef] [PubMed]

25. Ota, C.; Furukawa, T.; Shima, K.; Sano, S.; Kuramochi, K.; Tsubaki, K.; Noguchi, S.; Takano, K. Alkyne Tagged Raman Probes for Protein by Chemical Modification Approach. ChemistrySelect 2017, 2, 1267-1270. [CrossRef]

26. Möller, M.; Denicola, A. Study of Protein-Ligand Binding by Fluorescence. Biochem. Mol. Biol. Educ. 2002, 30, 309-312. [CrossRef]

27. Togashi, D.M.; Ryder, A.G. A Fluorescence Analysis of ANS Bound to Bovine Serum Albumin: Binding Properties Revisited by Using Energy Transfer. J. Fluoresc. 2008, 18, 519-526. [CrossRef]

28. Sudlow, G.; Birkett, D.J.; Wade, D.N. Further characterization of specific drug binding sites on human serum albumin. Mol. Pharmacol. 1976, 12, 1052-1061.

29. Ota, C.; Noguchi, S.; Tsumoto, K. The Molecular Interaction of a Protein in Highly Concentrated Solution Investigated by Raman Spectroscopy. Biopolymers 2015, 103, 237-246. [CrossRef]

30. Ota, C.; Noguchi, S.; Nagatoishi, S.; Tsumoto, K. Assessment of the Protein-Protein Interactions in a Highly Concentrated Antibody Solution by Using Raman Spectroscopy. Pharm. Res. 2016, 33, 956-969. [CrossRef]

31. Ota, C.; Takano, K. Behavior of Bovine Serum Albumin Molecules in Molecular Crowding Environments Investigated by Raman Spectroscopy. Langmuir 2016, 32, 7372-7382. [CrossRef] [PubMed]

32. Ota, C.; Suzuki, H.; Tanaka, S.I.; Takano, K. Spectroscopic Signature of the Steric Strains in an Escherichia coli RNase HI Cavity-Filling Destabilized Mutant Protein. J. Phys. Chem. B 2020, 124, 91-100. [CrossRef] [PubMed]

33. Kosower, E.M.; Kanety, H. Intramolecular Donor-Acceptor Systems. 10. Multiple Fluorescences from 8-(Phenylamino)-1Naphthalenesulfonates. J. Am. Chem. Soc. 1983, 105, 6236-6243. [CrossRef]

34. Chong, S.H.; Ham, S. Anomalous Dynamics of Water Confined in Protein-Protein and Protein-DNA Interfaces. J. Phys. Chem. Lett. 2016, 7, 3967-3972. [CrossRef] [PubMed] 
35. Sterpone, F.; Stirnemann, G.; Laage, D. Magnitude and Molecular Origin of Water Slowdown Next to a Protein. J. Am. Chem. Soc. 2012, 134, 4116-4119. [CrossRef]

36. Daniel, E.; Yang, J.T. Analysis of the Circular Dichroism of the Complexes of 8-Anilino-1-Naphthalenesulfonate with Bovine Serum Albumin. Biochemistry 1973, 12, 508-512. [CrossRef]

37. Bhattacharya, A.; Bhowmik, S.; Singh, A.K.; Kodgire, P.; Das, A.K.; Mukherjee, T.K. Direct Evidence of Intrinsic Blue Fluorescence from Oligomeric Interfaces of Human Serum Albumin. Langmuir 2017, 33, 10606-10615. [CrossRef]

38. Ota, C. Energy Transfer at Heterogeneous Protein-Protein Interfaces to Investigate the Molecular Behaviour in the Crowding Environment. Spectrochim. Acta Part. A Mol. Biomol. Spectrosc. 2017, 175, 145-154. [CrossRef]

39. Feng, X.-Z.; Lin, Z.; Yang, L.-J.; Wang, C.; Bai, C. Investigation of the Interaction Between Acridine Orange and Bovine Serum Albumin. Talanta 1998, 47, 1223-1229. [CrossRef]

40. Patra, S.; Santhosh, K.; Pabbathi, A.; Samanta, A. Diffusion of Organic Dyes in Bovine Serum Albumin Solution Studied by Fluorescence Correlation Spectroscopy. RSC Adv. 2012, 2, 6079. [CrossRef]

41. Anandakrishnan, R.; Aguilar, B.; Onufriev, A.V. H++ 3.0: Automating pK Prediction and the Preparation of Biomolecular Structures for Atomistic Molecular Modeling and Simulations. Nucleic Acids Res. 2012, 40, W537-W541. [CrossRef] [PubMed]

42. Schreiber, G.; Fersht, A.R. Rapid, Electrostatically Assisted Association of Proteins. Nat. Struct. Biol. 1996, 3, 427-431. [CrossRef] [PubMed]

43. Shen, B.-J.; Hage, T.; Sebald, W. Global and Local Determinants for the Kinetics of Interleukin-4/Interleukin-4 Receptor $\alpha$ Chain Interaction. Eur. J. Biochem. 1996, 240, 252-261. [CrossRef] [PubMed]

44. Georgiou, M.E.; Georgiou, C.A.; Koupparis, M.A. Automated Flow Injection Gradient Technique for Binding Studies of Micromolecules to Proteins Using Potentiometric Sensors: Application to Bovine Serum Albumin with Anilinonaphthalenesulfonate Probe and Drugs. Anal. Chem. 1999, 71, 2541-2550. [CrossRef]

45. Liu, Y.; Grimm, M.; Dai, W.T.; Hou, M.C.; Xiao, Z.X.; Cao, Y. CB-Dock: A web server for cavity detection-guided protein-ligand blind docking. Acta Pharmacol. Sin. 2020, 41, 138-144. [CrossRef] 